\title{
Behavioural responses to con- and heterospecific alarm cues by an alien and a coexisting native fish
}

\author{
Piotr Kłosiński (iD · Jarosław Kobak • Mateusz Augustyniak • Roman Pawlak • \\ Łukasz Jermacz • Małgorzata Poznańska-Kakareko • Tomasz Kakareko
}

Received: 30 January 2021/Revised: 27 October 2021/ Accepted: 10 November 2021/Published online: 27 November 2021

(C) The Author(s) 2021

\begin{abstract}
The monkey goby Neogobius fluviatilis is an invasive Ponto-Caspian fish that enters habitats of the native gudgeon Gobio gobio in European freshwaters, likely belonging to the same prey guild. Their abilities to detect and avoid predation have been poorly understood, although these traits may contribute to the competitive advantage and drive the invasion success of the goby. We tested intra- and interspecific responses of fish from sympatric populations to damage-released alarm cues (skin extract) in laboratory. Both species of fish responded to conspecific and heterospecific cues, but their responses to conspecifics were more diverse (changed social distancing among individuals, reduced vertical and horizontal movement) than those elicited by
\end{abstract}

Handling editor: Grethe Robertsen

Supplementary Information The online version contains supplementary material available at https://doi.org/10.1007/ s10750-021-04761-0.

P. Kłosiński (凹) · M. Augustyniak ·

R. Pawlak · Ł. Jermacz · T. Kakareko

Department of Ecology and Biogeography, Faculty of Biological and Veterinary Sciences, Nicolaus Copernicus University, Lwowska 1, 87-100 Toruń, Poland

e-mail: klosinski.piotr@doktorant.umk.pl

J. Kobak · M. Poznańska-Kakareko

Department of Invertebrate Zoology and Parasitology, Faculty of Biological and Veterinary Sciences, Nicolaus

Copernicus University, Lwowska 1, 87-100 Toruń, Poland heterospecifics (changed social distancing only). Moreover, the fish differed in their anti-predation behaviour: the gudgeon increased whilst the monkey goby decreased inter-individual distances and only the gudgeon exhibited thigmotaxis and reduced mobility in response to the conspecific cues. Interspecific differences show that the species exhibit distant antipredation strategies. This might be associated with their phylogenetic distance and/or higher differentiation of their ecological niches than commonly assumed. Besides, our results suggest that alien species be included in the interspecific exchange of information in local fish assemblages.

Keywords Anti-predator responses - Chemical alarm cues - Gobio gobio - Neogobius fluviatilis . Invasive species $\cdot$ Schreckstoff

\section{Introduction}

For the past five decades, biological isolations have been gradually eliminated through global changes (Vilà et al., 2010; Keller et al., 2011; Early et al., 2016), resulting in coexistence of species that used to be geographically separated. This involves changes in prey guilds, i.e. groups of species that share the same predators and co-occur temporally and spatially (Mirza \& Chivers, 2001; Pollock et al., 2003). The native members of the guild start to interact with 
newly arrived incomers sharing no common coevolutionary history (Brown \& Godin, 1997). In aquatic environments, especially in freshwater ecosystems, which are among the most invaded habitats in the world (Strayer, 2010; Ricciardi \& MacIsaac 2010), interactions among formerly allopatric, now sympatric, fish species are particularly relevant because fish belong to the most commonly introduced animals into inland water systems (Keller et al., 2011). Moreover, fish, as organisms occupying higher trophic levels, can have a large cascading impact on communities and food webs (Gallardo et al., 2016).

During the past few decades, the rapid expansion of several goby fish (Gobiidae), originating from the Ponto-Caspian region, has been observed in both freshwater and marine ecosystems worldwide (Copp et al., 2005; Roche et al., 2013) with an ample potential to alter food webs, including predator-prey relationships (Barton et al., 2005). The gobies are small-sized benthic fish (mostly up to several $\mathrm{cm}$ in total length) commonly consumed by native predators (Reyjol et al., 2010; Płąchocki et al., 2012; Mikl et al., 2017). In European inland waters, the gobies spread mainly in large rivers, including the River Danube (Jurajda et al., 2005), Rhine (Borcherding et al., 2011) and Vistula (Płąchocki et al., 2020). Because there are no native Gobiidae species in these waters, the only possible option for the alien gobies is to join bottomdwelling fish assemblages composed of species distantly related to them, belonging to other families. There is a growing number of studies comparing the alien gobies and such coexisting native fish in terms of various ecological aspects, such as competitive interactions for food/space (Van Kessel et al., 2011; Kakareko et al., 2013; Grabowska et al., 2016), habitat partitioning (Kakareko et al., 2016), feeding preferences (Błońska et al., 2016), and swimming performance (Egger et al., 2021). However, still little is known on how the gobies compare to local fish of the same prey guild in their behaviour of detection and avoidance of predation.

Chemical cues play an important role in information transfer in aquatic environments, especially in turbid and vast waters where the use of visual and auditory perception is limited (Brönmark \& Hansson, 2000; Burks \& Lodge, 2002; Chung-Davidson et al., 2010). In aquatic animals, scents mediate all basic life functions, such as reproduction, food location, predation avoidance and orientation in space (Liley, 1982;
Hay, 2009; Brönmark \& Hansson, 2000). One of the essential cues used by animals for anti-predator defence is alarm cues released into water from damaged tissue of injured prey (Wisenden, 2015; Chivers \& Smith, 1998; Wisenden \& Chivers, 2006; Crane et al., 2013). They are released immediately after a predator attack, indicate high predation risk and provide reliable (context-specific) public information to guide behavioural responses of nearby animals to minimize the risk of encountering a predator (Smith, 1992; Ferrari et al., 2010; Chivers et al., 2013). Among fish, the largest and most diverse group of vertebrates (Sorensen, 2015), these unambiguous alarm cues can invoke a widespread response of potential prey individuals, including heterospecifics that are able to use such public information (Wisenden, 2003; Mathis \& Smith, 1993a). Such an ability to respond to heterospecific alarm cues in mixed species groups may most likely occur when prey species are closely phylogenetically related and belong to the same prey guild (Mathis \& Smith, 1993b; Mirza \& Chivers, 2001; Wisenden \& Chivers, 2006; Pollock et al., 2003; Dalesman et al., 2007). However, even if members of a prey guild are phylogenetically distant, the natural selection can favour cross-species communication among them, as shown for a benthic fish, the rainbow darter Etheostoma caeruleum Storer, 1845, and the Oklahoma salamander Eurycea tynerensis Moore and Hughes, 1939 (Anderson \& Mathis, 2016). On the other hand, fish evolved optimal trade-offs between benefits and costs of executing adaptive behavioural anti-predator responses (Allan, 1982; Stabell \& Lwin, 1997; Ferrari et al., 2010; Landeira-Dabarca et al., 2019). Thus, different species within a prey guild are likely to vary in their finely tuned mechanisms to detect the chemical alarm cues and to respond accordingly (Lima \& Dill, 1990; Chivers \& Smith, 1998; Mirza et al., 2003). These differences are likely to translate to inter-specific differences in competitive ability and spreading potential. In aquatic environments, invasive crustaceans are known to be able to outcompete native species due to better sensory detection of predators, manifested by the use of a broader range of chemical information and/or faster escape responses (Weis, 2016; Hazlett et al., 2003). The intriguing question is whether this phenomenon applies to various taxonomic groups of invasive species. Here, we raise the question whether the Ponto-Caspian gobiids, despite being recently 
established in Polish fresh waters (about two decades ago) and phylogenetically distant from native members of their prey guild in newly invaded areas (Grabowska et al., 2010), can exchange chemical alarm cues with the native prey guild members. They may support and/or benefit from aggregate antipredatory defence behaviours of local fish communities, depending on whether they are effective donors and/or receivers of heterospecific cues.

In this study, we investigated anti-predation behaviour of two fish that co-occur in European waters and fit well into the context described above: (1) the invasive monkey goby Neogobius fluviatilis (Pallas, 1814), and (2) the native gudgeon Gobio gobio (Linnaeus, 1758). The monkey goby is one of the successful invaders of Ponto-Caspian origin in European fresh waters (Č́ápová et al., 2008; Kakareko et al., 2009; Plachá et al., 2010), locally dominating in goby assemblages (Płąchocki et al., 2020). This alien species enters habitats occupied by the gudgeon, as both species are mostly associated with sandy bottom areas (Bănărescu et al., 1999; Čápová et al., 2008; Jakubčinová et al., 2017; Płąchocki et al., 2020). It has been pointed out that declines in gudgeon populations coincide with increasing monkey goby population densities (Jakovlić et al., 2015). The gudgeon and monkey goby seem to occupy similar ecological niches (Jakovlić et al., 2015; Borcherding et al., 2016). Due to the occurrence in similar habitats and similar morphology (size mostly up to several $\mathrm{cm}$ of standard length, streamlined shape, dappled coloration) and ecology (bottom feeders) (Kottelat \& Freyhof, 2007; Plachá et al., 2010), the two species are likely to share the same predators. Therefore, the two species are a useful case model to study associations and interactions between the Ponto-Caspian invaders and their native counterparts in the light of their responses to predation pressure. The monkey goby and gudgeon are phylogenetically distant from each other, belonging to different orders: Gobiiformes and Cypriniformes (Nelson et al., 2016), respectively. They do not have a long common evolutionary history, but in the Ponto-Caspian region the goby co-exists with several species closely phylogenetically related to the gudgeon (Naseka \& Bogutskaya, 2009; Mendel et al., 2008). We examined differences between the alien monkey goby and native gudgeon in their early detection and avoidance of predation through the use of alarm cues. Using a laboratory behavioural assay, we tested behavioural responses of the fish to conspecific and heterospecific damage-released chemical alarm cues (skin extracts). We hypothesized that:

(1) Both fish are responsive not only to conspecific but also to heterospecific alarm cues. The responses to both cues are manifested by increased aggregation and thigmotaxis, as well as reduced horizontal and vertical movements.

(2) The fish differ from each other in the quality and strength of their responses to the damagereleased alarm cues. The alien species exhibits more pronounced responses to the cues (thus maximizing its security in a mixed-species assemblage), or, alternatively, is less reactive to the cues (thus being able to partition more energy into growth and reproduction than its native counterparts).

\section{Materials and methods}

\section{Animals}

We collected fish of both species using electrofishing (EFGI 650, BSE Bretschneider Spezialelektronik, Germany) in June 2018, in the longest tributary of the River Vistula, the River Pilica near the city of Warka (51 $45^{\prime} 49.0^{\prime \prime} \mathrm{N} 21^{\circ} 08^{\prime} 56.7^{\prime}$ 'E), east-central Poland. We caught them from the same shallow (depth: $0.2-0.5 \mathrm{~m}$ ) near-shore area with moderate water flow and sandy bottom. The exact date of the monkey goby introduction to the River Pilica is not known, but during extensive research in 2003-2005, the monkey goby were not recorded in the area (Penczak et al., 2006). Thus, the fish have been living in sympatry in the area for no more than 14 years at the time of their collection. Immediately after capture, we transported the animals to the laboratory (ca. $3 \mathrm{~h}$ transport time) in plastic bags with aerated water. In the laboratory, we placed the fish in 350-L stock tanks (15-20 individuals per tank, both species together) equipped with standard aquarium filters and aerators and filled with conditioned tap water. A temperature of $20{ }^{\circ} \mathrm{C}$, which corresponds to mean summer temperatures recorded in rivers in central Poland (Łaszewski, 2018), was maintained by air-conditioning; the photoperiod was set to $12 \mathrm{~h}$ day: $12 \mathrm{~h}$ night. Light intensity at the bottom of the tanks was $5 \mathrm{~lx}$ (measured by a 
light meter L-20A, Sonopan Ltd., Białystok, Poland). The stock tanks were equipped with ceramic shelters and had no bottom substrate. We fed the fish ad libitum daily with frozen chironomid larvae and exchanged water in the stock tanks once a week (ca. $30 \%$ of the water volume). We kept the fish in the stock tanks for at least 1 month before the start of experiments. The total length of the fish (measured using ImageJ $1.49 \mathrm{v}$, freeware by W.S. Rasband, U.S. National Institutes of Health, Bethesda, Maryland, USA: https://imagej.nih. gov/ij, from digital photographs taken during tests) was $75 \mathrm{~mm}$ (min-max: 44-96 mm) and $67 \mathrm{~mm}$ (45-97 mm) for gudgeons and gobies, respectively. The length difference between the two fish, although relatively small, was significant (t-test: $\mathrm{t}_{94}=3.65$, $P<0.001)$. We took the fish for the experiment randomly, firstly from the river and then from the stock tanks, thus the interspecific length differences reflected natural differences in the size of individuals between the coexisting populations. The individuals used for the tests had virtually no external symptoms of sexual maturity and sexual dimorphism characteristics, and we did not determine their sex. We collected and used the fish under permit of the Local Committee for Ethics in Animal Research in Bydgoszcz, Poland, statement no. 50/2017 from 28 September 2017. All procedures using fish met the European Union guidelines on the protection of animals used for scientific purposes (Directive 2010/63/ UE).

\section{Preparation of alarm cues}

We prepared two consecutive samples of the damagereleased chemical alarm cue during the study. Each time, we took 3-7 donor individuals of each species from the stock tank, stunned them by a blow to the head and then severed their spinal cord. To obtain the chemical cue, whose sources are located in the epidermal layer (for review, see Ferrari et al., 2010), we gently removed skin patches from the dorsal and lateral parts of the body using a scalpel and tweezers ( $1 \mathrm{~g}$ total skin weight), homogenized them in $100 \mathrm{ml}$ of chilled $\left(4^{\circ} \mathrm{C}\right)$ distilled water (all the donors of the same species pooled) and filtered through qualitative cellulose filters Whatman no. $1(11 \mu \mathrm{m})$ to remove any particles, yielding the skin homogenate (Pollock et al., 2003; Souza-Bastos et al., 2014). We collected the filtrate into 2-ml plastic Eppendorf tubes, and stored at $-80{ }^{\circ} \mathrm{C}$ until use (no longer than for a month). This ultra-low temperature is recommended for long-term storage of biological samples like sex hormones (Tworoger \& Hankinson, 2006). Such pooled signal samples allowed us to reduce potential intraspecific differences in signal strength and focus on fish responses to typical cues representative of particular species. We also froze distilled water for use in control conditions in the same way.

\section{Experimental setup}

We conducted experiments in $84-\mathrm{L}$ glass tanks (bottom: $60 \times 40 \mathrm{~cm}$, height: $35 \mathrm{~cm}$, water level: $28 \mathrm{~cm}$, water volume $67.2 \mathrm{~L})$ filled with settled, aerated tap water, without any bottom substrate. To reduce the impact of external disturbances on the fish, we isolated the tanks on all sides with Styrofoam screens. Each tank was equipped with a standard aquarium filter (in the corner) and aerator. A single dose of the cue was taken from pooled contents of nine Eppendorf tubes with the stored extract (alarm substance) or distilled water (control cue). We thawed the cue at $20{ }^{\circ} \mathrm{C}$ and immediately added it to the experimental tank by use of a peristaltic pump (Watson-Marlow 323U, Falmouth, United Kingdom) at a rate of $19.8 \mathrm{ml} \mathrm{min}^{-1}$ (accuracy to the nearest $0.1 \mathrm{ml} \mathrm{min}^{-1}$ ). The cue fully reached the water column of the tank in $50 \mathrm{~s}$. Thus, a single dose of the cue consisted of $16.5 \mathrm{ml}$ of the alarm substance (i.e. skin extract obtained from $0.165 \mathrm{~g}$ of the tissue). Immediately before the injection of the test substance, we filled the outlet tube of the peristaltic pump with fresh water from the tank by use of reverse operation of the pump to avoid pumping air bubbles to the tank. The outputs of the peristaltic pump (vinyl tubes with an inner diameter of $1.59 \mathrm{~mm}$ ) were attached near the output nozzle of the aquarium filter, which provided water movement distributing the cue in the water column and creating conditions similar to natural riverine habitats where both species occur. We recorded the experiment using an IP video camera (SNB-6004P, Samsung, South Korea) placed $1 \mathrm{~m}$ above the water level in the tank. The camera was facing down to catch the view of the entire tank from above. 
Experimental procedure

We tested responses of triplets (i.e. 3 conspecifics placed together in the same tank) of the two fish species to conspecific and heterospecific alarm cues. The triplets consisted of individuals collected randomly from the same stock tank, and thus were familiar to one another from the beginning of the test. Each individual was used only once in the experiment. We selected this number of individuals during preliminary observations, which indicated that fish in such groups behave naturally in contrast to pairs or singletons. Each of the two treatments, i.e. fish exposed to conspecific or heterospecific alarm cues, was replicated 8 times $(n=8)$. In total, 96 individuals were tested $(2$ species $\times 2$ treatments $\times 3$ individuals $\times 8$ replicates).

Acclimation of fish to experimental conditions after transferring them to the experimental tank lasted for $72 \mathrm{~h}$. During the acclimation period, we fed the fish daily with frozen chironomid larvae ad libitum. The last feeding took place $12 \mathrm{~h}$ before the beginning of the experiment. An extended acclimation period ensured that the experiment would not be disturbed by the presence of the camera. At the end of the acclimation period, individuals of both species behaved naturally, i.e. explored the environment, did not cling to the wall of the tank, did not hide behind the filter and did not exhibit any rapid erratic swimming. We carried out the experiments during the daytime, between 7:00 and 12:00, when the activity of the fish, based on our preliminary observations, was highest. We established the duration of the experiment and dose of the alarm cue on the basis of preliminary research and literature data (Mathuru, 2016; Pollock et al., 2003; Souza-Bastos et al., 2014). One replicate lasted for $18 \mathrm{~min}$ and consisted of two consecutive 9-min periods (Fig. 1). We injected distilled water (control cue) into the experimental tank at the beginning of the first period to make it a control period. Then, at the beginning of the second period, we injected the alarm substance to the tank (to observe fish responses to the alarm cue, compared to their regular behaviour during the control period). We counted the exposure time from the moment when the first drop of the dosed substance reached the experimental tank. It is worth noting that the duration of the test itself (18 min) was much shorter than the entire stay and pre-experimental acclimation of the fish in the experimental tank $(72 \mathrm{~h})$ and the period of their maximum activity $(5 \mathrm{~h}$ ) (during which the tests were conducted exclusively). Therefore, it is highly unlikely that any time-related changes in fish behaviour obscured or masked the potential effect of the stimulus during the tests. We conducted all tests at the same temperature, photoperiod and light intensity as those set in the stock tanks.

Processing video data

We split each 9-min test period (with control water or the alarm substance) into three 3-min sub-periods (Fig. 1). This allowed us to test the effect of time after the cue application on fish responses and to detect immediate behavioural changes occurring only at the first contact with the cue. We used VirtualDub 1.10.4 (freeware by Avery Lee, www.virtualdub.org/index) to extract video frames from the recorded videos, which facilitated determination of behavioural variables and ensured better precision. Because the individuals were visually very similar to one another, it was not possible to track them without mistaking particular individuals on video frames. Instead, we tracked the entire group of three individuals; thus a replication of the experiment was the responses of all individuals in the group, which were summed up and averaged (see below for the details). We measured all necessary distances in these frames, using ImageJ $1.49 \mathrm{v}$, with the centre of the fish head (established as an equidistant point between the eyes) as a reference point (Online Resource 1A, C). We manually noted four anti-predation behavioural responses (Chivers \& Smith, 1998) of the tested fish for each experimental sub-period:

1. Thigmotaxis $(T)$. This was the average distance of individuals to the nearest tank wall measured in 6-s intervals (Online Resource 1A) and calculated according to the following formula:

$$
T=\frac{D W}{(3 \times 30)}
$$

where: $D W$ - the total sum of measured distances of individuals to the nearest tank wall, 3 - the number of individuals in the tested group, 30 - the number of frames (measurements) per sub-period. The filter in the tank was treated as part of the wall, i.e. if a fish was closer to the filter than to the glass 


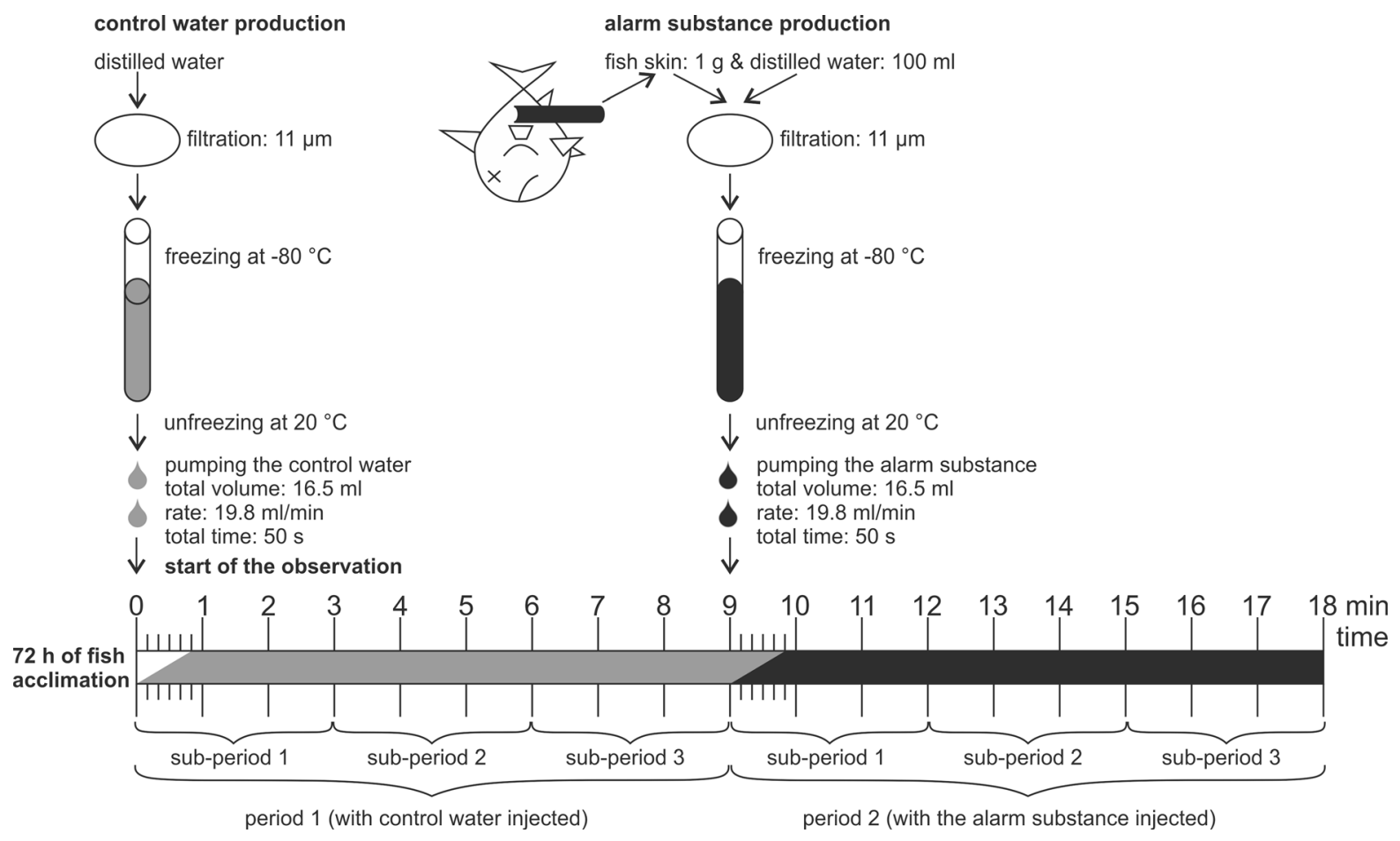

Fig. 1 Experimental setup

wall, the distance to the filter was taken into account). We used only cases where a fish had contact with the bottom, i.e. did not move up to the water column (Online Resource 1B), assuming that the corner between the vertical wall and bottom of the tank provides a fish with shelter.

2. Relations with conspecifics (R). This was the average horizontal distance of individuals to their nearest neighbour, measured in 6-s intervals (Online Resource 1A) and calculated according to the following formula:

$R=\frac{D N}{(3 \times 30)}$

where: $D N$ - the total sum of measured distances of individuals to their nearest neighbours, 3 - the number of individuals in the tested group, 30 - the number of frames (measurements) per sub-period.

3. Immobility (I). This was the average percentage of time spent by individuals without movement, calculated according to the following formula:
$I=\frac{S P}{(3 \times 29)} \times 100$

where: $S P$ - the total number of cases when an individual stayed in the same position in neighbouring video frames $6 \mathrm{~s}$ apart, 3 - the number of individuals in the tested group, 29 - the number of frame transitions (measurements) per sub-period. We assumed a fish to move when its horizontal displacement between the frames was equal to or longer than its body length (Online Resource 1C).

4. Vertical movement frequency: determined as binary events (present/not present) when at least one individual was observed to swim up to the water column (Online Resource 1B) and then sank to the bottom. To notice such events and collect quantitative data for analysis, each experimental sub-period was divided into nine 20-s intervals (more useful than frames for seeing these events from above, as established in preliminary trials). If at least one vertical movement occurred during a given interval, it was counted as one event. Thus, the number of vertical movement events that could be observed during each 3-min sub-period ranged from 0 to 9 . 
Statistical analysis

We were interested mainly in qualitative or quantitative differences in species behavioural responses to the alarm cues, rather than in general interspecific differences in activity or distances kept by the fish. Therefore, we conducted analyses separately for each species. Thus, to control for the inflated type I error rate, we considered the main effects and interactions as statistically significant at $P<0.025$ (Bonferroni correction for 2 analyses). We log-transformed the thigmotaxis, distance among conspecifics and immobility variables to achieve normality and analysed them using a General Linear Model. We tested the frequency of vertical movements using a Generalized Linear Model with binomial distribution (vertical movement observed or not during each of 9 intervals) and log link function. Each model included alarm source (conspecific or heterospecific) as a betweensubject factor, as well as cue type (consecutive 9-min periods with distilled water or alarm substance as a cue) and exposure time (consecutive $0-3,3-6$ or 6-9 min sub-periods within each 9-min period, see Processing video data for description) as withinsubject factors. Initially, we included all main effects and interactions and then applied backward simplification of the models by removing non-significant higher-order interactions.

When both species displayed a qualitatively similar response to the alarm cue (which happened only in the case of vertical movements, see the Results), we checked whether the strength of their responses differed between the species. For each replicate, we calculated a relative change in fish behaviour $(\mathrm{Ch})$ after the application of the alarm cue compared to the corresponding sub-period (0-3, 3-6 and 6-9 min) after the application of the control cue:

$C h=\frac{B_{\text {Alarm }}-B_{\text {Control }}}{B_{\text {Alarm }}+B_{\text {Control }}}$

where $\mathrm{B}_{\mathrm{Alarm}}, \mathrm{B}_{\mathrm{Control}}$ are the measurements of the behaviour of fish exposed to the alarm cue and control cue, respectively. Higher values of this index indicate a greater change in fish behaviour relative to its absolute magnitude.

We analysed these indices using General Linear Models including species as a between-subject factor and exposure time (the three sub-periods after the cue application) as a within-subject factor. We only used responses to conspecific alarm cues in these analyses, as fish changed significantly the analysed behaviours only in response to that cue (see the Results).

We further examined significant model effects using sequential-Bonferroni-corrected pairwise Fisher LSD tests (for the General Linear Models) and pairwise contrasts (for the Generalized Linear Model).

We used IBM SPSS Statistics 25.0 for the statistical analysis (IBM Inc., USA).

\section{Results}

Compared to the control period, gudgeon stayed closer to the tank walls when exposed to conspecific alarm cues, but not in the presence of heterospecific alarm cues (Fig. 2), as shown by a significant alarm source $\mathrm{x}$ cue type interaction (Table 1A, Online Resource 2A). Monkey goby did not change their position relative to the tank walls in response to any stimuli applied in the experiment (Table 1A).

Distances among gudgeon individuals increased in response to both conspecific and heterospecific alarm sources, though only during the first 3-min period after

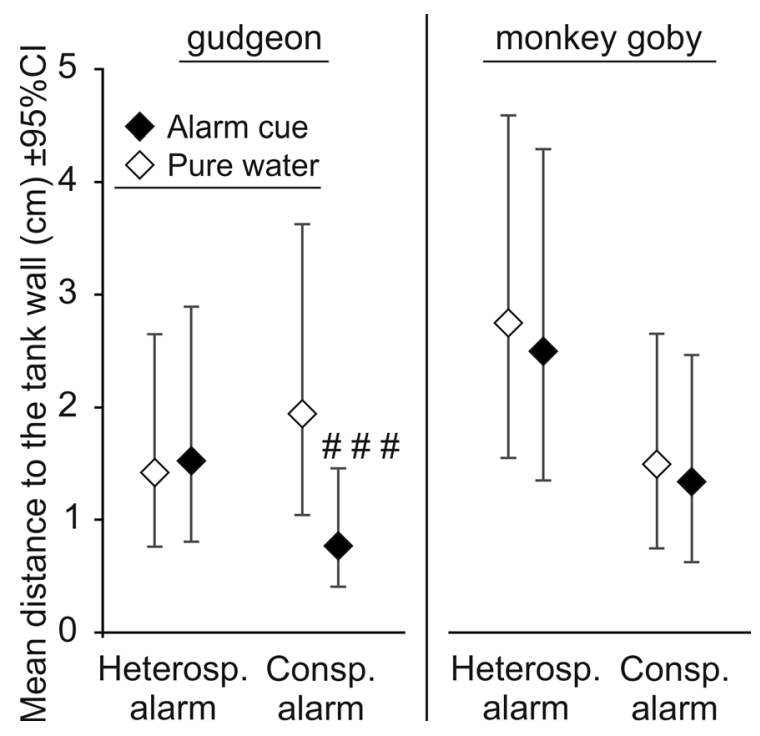

Fig. 2 Thigmotaxis responses of monkey gobies and gudgeons to conspecific and heterospecific alarm cues. Presented values (back-transformed after the analysis of log-transformed data) are means predicted by the General Linear Models (Table 1A). Time of exposure to the cue is not included (pooled) as nonsignificant in the models. Hashtags (\#) indicate significant differences in the behaviour of animals exposed to the control water and alarm cue: ${ }^{\# ~ \# ~} P<0.001,{ }^{\# ~} P<0.01,{ }^{\#} P<0.05$ 
Table 1 Analysis of the impact of alarm cue source (conspecific or heterospecific), cue type (pure water or alarm substance applied to the tank in two consecutive 9-min intervals) and exposure time (0-3, 3-6 or 6-9 min after the application of the cue) on the behaviour of gudgeon and monkey goby

\begin{tabular}{|c|c|c|c|c|}
\hline Species & Effect & $\mathrm{df}$ & $\mathrm{F}$ & $P$ \\
\hline \multirow[t]{4}{*}{ Gudgeon } & Alarm source & 1,14 & 0.21 & 0.656 \\
\hline & Cue type & 1,59 & 16.66 & $<0.001^{\#}$ \\
\hline & Exposure time & 2,41 & 0.43 & 0.652 \\
\hline & Source*Cue type & 1,58 & 22.84 & $<0.001^{\#}$ \\
\hline \multirow[t]{3}{*}{ Goby } & Alarm source & 1,14 & 2.65 & 0.126 \\
\hline & Cue type & 1,46 & 0.57 & 0.454 \\
\hline & Exposure time & 2,23 & 0.49 & 0.618 \\
\hline \multirow[t]{4}{*}{ Gudgeon } & Alarm source & 1,14 & 0.37 & 0.551 \\
\hline & Cue type & 1,57 & 0.58 & 0.450 \\
\hline & Exposure time & 2,38 & 0.88 & 0.425 \\
\hline & Cue type*Time & 2,38 & 5.44 & $0.008^{\#}$ \\
\hline \multirow[t]{3}{*}{ Goby } & Alarm source & 1,13 & 4.20 & 0.061 \\
\hline & Cue type & 1,53 & 9.62 & $0.003^{\#}$ \\
\hline & Exposure time & 2,46 & 1.39 & 0.259 \\
\hline \multirow[t]{4}{*}{ Gudgeon } & Alarm source & 1,29 & 0.21 & 0.650 \\
\hline & Cue type & 1,43 & 11.97 & $0.001^{\#}$ \\
\hline & Exposure time & 2,20 & 0.13 & 0.877 \\
\hline & Source*Cue type & 1,42 & 12.86 & $0.001^{\#}$ \\
\hline \multirow[t]{3}{*}{ Goby } & Alarm source & 1,14 & 0.47 & 0.502 \\
\hline & Cue type & 1,58 & 0.27 & 0.603 \\
\hline & Exposure time & 2,39 & 1.61 & 0.212 \\
\hline \multirow[t]{4}{*}{ Gudgeon } & Alarm source & 1,90 & 0.54 & 0.464 \\
\hline & Cue type & 1,90 & 24.74 & $<0.001^{\#}$ \\
\hline & Exposure time & 2,90 & 0.88 & 0.419 \\
\hline & Source*Cue type & 1,90 & 27.26 & $<0.001^{\#}$ \\
\hline \multirow[t]{4}{*}{ Goby } & Alarm source & 1,90 & 1.21 & 0.275 \\
\hline & Cue type & 1,90 & 0.45 & 0.504 \\
\hline & Exposure time & 2,90 & 6.35 & $0.003^{\#}$ \\
\hline & Source*Cue type & 1,90 & 8.32 & $0.005^{\#}$ \\
\hline
\end{tabular}

B. Distance among fish

(General linear model)

D. Vertical movements

(Generalized linear model, binomial distribution, log link function)

(General inear model)

\begin{abstract}
C. Immobility time
(General linear model)
\end{abstract}

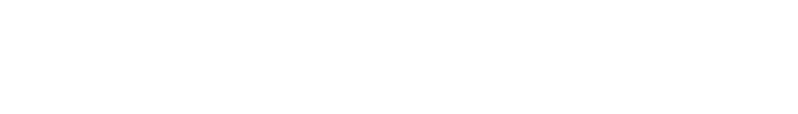

Response variable

A. Thigmotaxis (distance to the tank wall)

(General linear model)

Cue type and exposure time were included in the models as within-subject factors. Non-significant higher order interactions were dropped to simplify the models

Hashtags (\#) indicate significant effects with a Bonferroni correction for two separately analysed species $(P<0.05 / 2=0.025)$

cue application (Fig. 3), as shown by a significant cue type $\mathrm{x}$ exposure time interaction, as well as nonsignificant model terms involving the alarm source (Table 1B, Online Resource 2B). Monkey goby stayed closer to one another when exposed to conspecific and heterospecific alarm sources compared to control conditions, irrespective of the exposure time (Fig. 3), as shown by a significant main effect of cue type (Table 1B).
Immobility time of gudgeon depended on a significant alarm source $\mathrm{x}$ cue type interaction (Table 1C, Online Resource 2C), whereas monkey goby did not change their horizontal mobility in response to any alarm cues. Gudgeon moved less in the presence of conspecific alarm cues, but not in response to heterospecific alarm cues (Fig. 4).

Vertical movements of both species depended on a significant alarm source $\mathrm{x}$ cue type interaction 


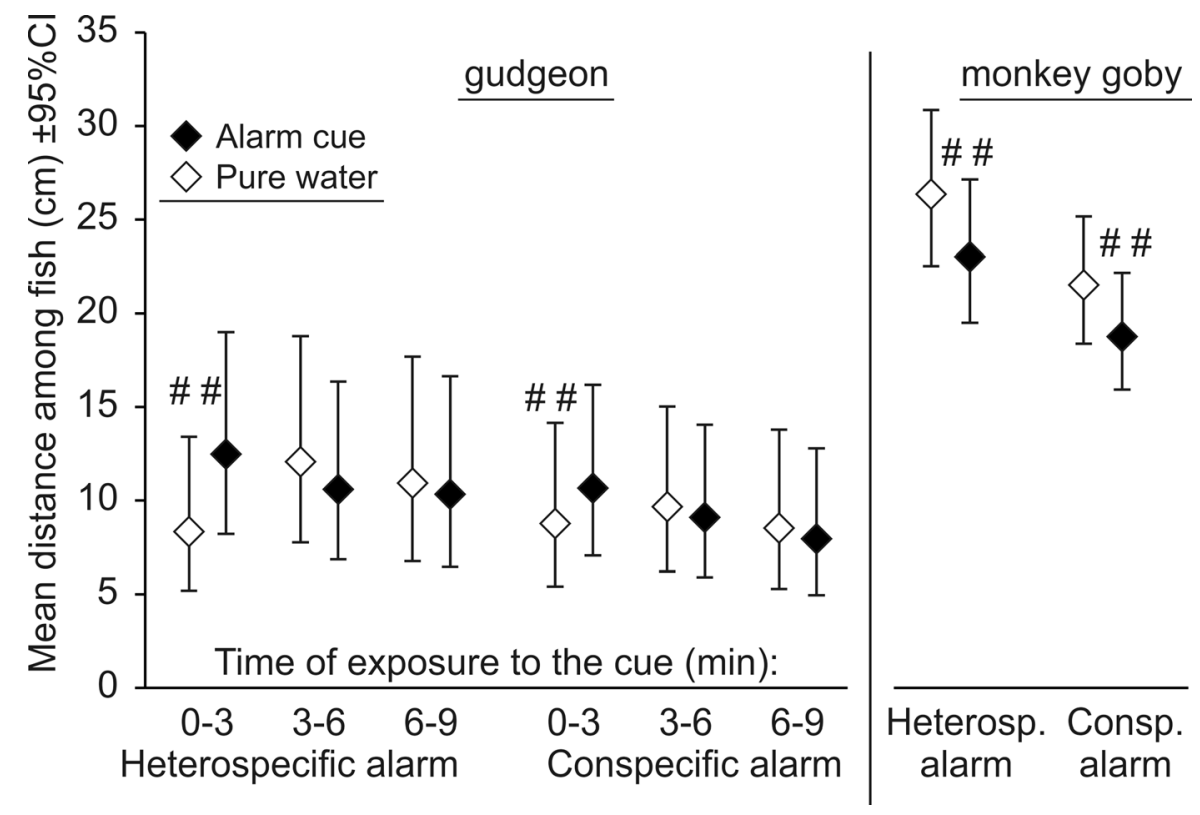

Fig. 3 Social distancing responses of monkey gobies and gudgeons to conspecific and heterospecific alarm cues depending on exposure time after receiving the cues. Presented values (back-transformed after the analysis of log-transformed data) are means predicted by the General Linear Models (Table 1B).

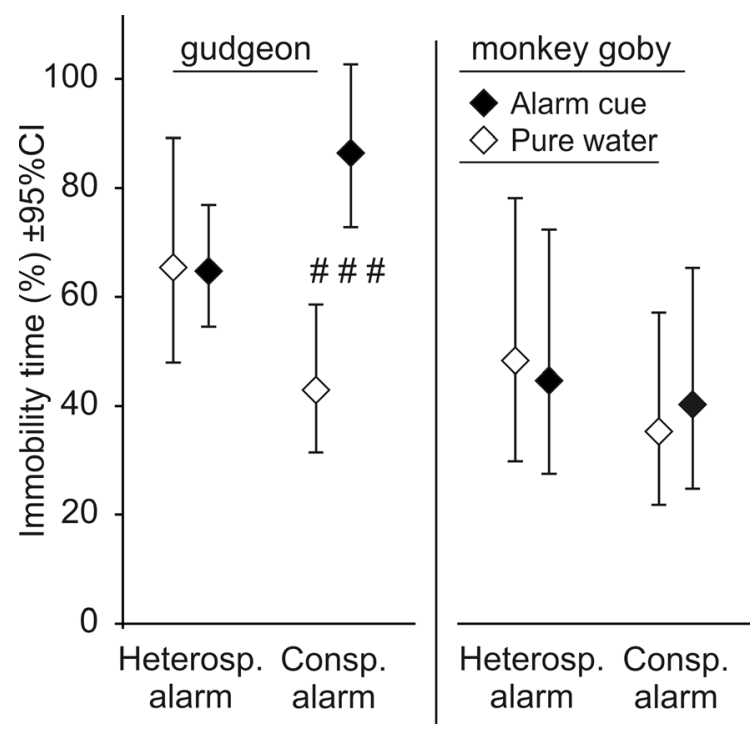

Fig. 4 Immobility responses of monkey gobies and gudgeons to conspecific and heterospecific alarm cues. Presented values (back-transformed after the analysis of log-transformed data) are means predicted by the General Linear Models (Table 1C). Time of exposure to the cue is not included (pooled) as nonsignificant in the models. Hashtags (\#) indicate significant differences in the behaviour of animals exposed to the control water and alarm cue: ${ }^{\# ~} P<0.001,{ }^{\# ~} P<0.01,{ }^{\#} P<0.05$
Time of exposure to the cue is not included (pooled) for the monkey goby as non-significant in the model. Hashtags (\#) indicate significant differences in the behaviour of animals exposed to the control water and alarm cue: \# \# $P<0.001$, ${ }^{\#} P<0.01,{ }^{\#} P<0.05$

(Table 1D, Online Resource 2D). In the presence of conspecific alarm cues, the fish more often stayed on the tank bottom compared to the control period (Fig. 5). Heterospecific alarm cues did not cause any changes in vertical movement of fish. The responses of gudgeon were generally stronger than those of monkey goby (Fig. 5), which was confirmed by a significant effect of species in the analysis of relative changes in fish vertical movements (mean relative change \pm SE: $71 \pm 28$ and $15 \pm 28 \%$ for the gudgeon and monkey goby, respectively) (Table 2).

\section{Discussion}

The first noteworthy finding of our study is the indication that, in accordance with our first hypothesis, the two phylogenetically distant species with a short history of co-existence are able to respond to heterospecific alarm cues from each other. This finding opens the possibility that $N$. fluviatilis, which is a successful invasive fish species in European freshwaters (Płąchocki et al., 2020), has a potential to affect native fish communities not only negatively, but 


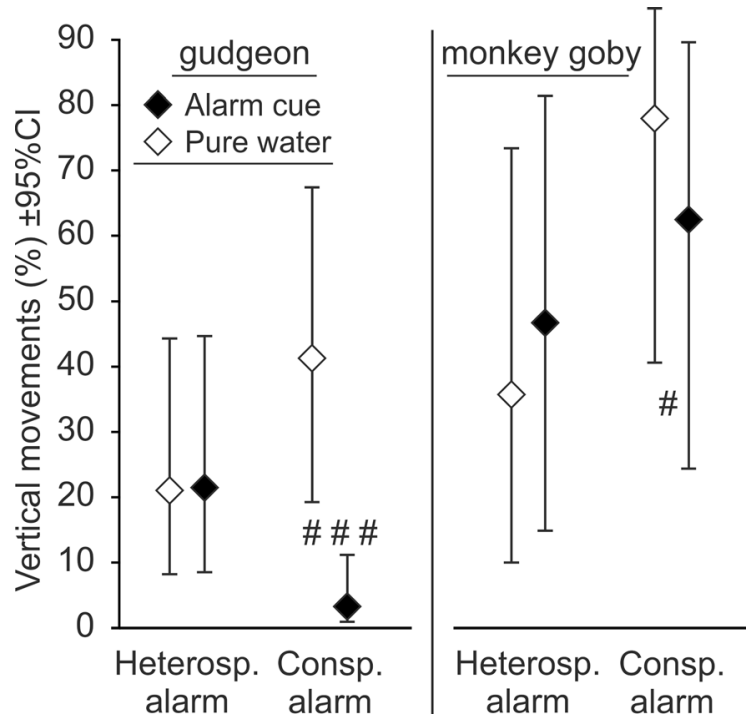

Fig. 5 Vertical movement responses (percentages of 20-s intervals with vertical movements) of monkey gobies and gudgeons to conspecific and heterospecific alarm cues. Presented values are means predicted by the Generalized Linear Model (binomial distribution, log-link function) (Table 1D). Time of exposure to the cue is not included (pooled) as nonsignificant in the models. Hashtags (\#) indicate significant differences in the behaviour of animals exposed to the control water and alarm cue: ${ }^{\# ~} P<0.001,{ }^{\# ~} P<0.01,{ }^{\#} P<0.05$

Table 2 Analysis of the change in vertical movements of the studied species (gudgeon vs. monkey goby) exposed to the conspecific alarm cue relative to their behaviour in the presence of the control cue (pure water) after various exposure times $(0-3,3-6$ or $6-9$ min after the application of the cue)

\begin{tabular}{lllll}
\hline Response variable & Effect & df & F & $P$ \\
\hline Vertical movements & Species & 1,12 & 9.52 & $0.009^{\#}$ \\
& Exposure time & 2,19 & 2.01 & 0.161 \\
\hline
\end{tabular}

The analysis was conducted for this response variable, for which both fish species displayed a similar response type. Exposure time was included in the model as a within-subject factor. Non-significant interactions were dropped to simplify the models

Hashtags (\#) indicate significant effects $(P<0.05)$

also positively. They can act as eavesdropping competitors (Anderson \& Mathis, 2016), but also as supportive companions for native prey species in early detection of predator presence, being both receivers and donors (senders) of the public alarm cues. The use of heterospecific alarm cues likely provides a greater amount and broader range of information about the environmental predation risk compared to what can be obtained from conspecifics (Seppänen et al., 2007). Thus, our results put it forward for consideration that a native species might sometimes benefit from the presence of alien species (Pollock \& Chivers, 2004; Pollock et al., 2003). How much this matters for the fitness of the studied species is an open question, given that we showed much more pronounced behavioural responses to conspecific alarm cues compared to those to heterospecific cues. Notwithstanding these differences, it should be emphasized that invasive species affect simultaneously multiple aspects of their environment and invaded communities, thus it is likely that the net effect of the monkey goby on the local benthic fish assemblage would be negative, even if any benefits from interspecific enhancement of anti-predator defences do exist. It is worth considering that the result may also apply to other, closely phylogenetically related Ponto-Caspian goby species as members of a single clade within the family (Thacker \& Roje, 2011).

Here, we tested specifically $N$. fluviatilis living in sympatry with G. gobio for up to 14 years and lacking a long coevolutionary history (see Materials and methods). Thus, we observed interspecific interactions probably mainly developed over such a period. However, it cannot be ruled out that the two species have shared common alarm substances, as these chemicals are conserved across fish taxa and neither sympatry nor phylogenetic relatedness are necessary for recognition of heterospecific alarm cues in this taxonomic group (Magellan et al., 2020). It is worth emphasizing that G. gobio is absent from the PontoCaspian region, while $N$. fluviatilis co-occurs in its native Ponto-Caspian area with other species of the genus Gobio (Naseka \& Bogutskaya, 2009; Copp et al., 2005; Mendel et al., 2008; Roche et al., 2013), closely related to G. gobio. Thus, in contrast to the gudgeon, the monkey goby had a chance to evolve recognition mechanisms towards gudgeon alarm cues (Pollock \& Chivers, 2004). Nonetheless, we found that both of the two co-existing species responded to heterospecific alarm cues, though, as we mentioned earlier, the heterospecific responses were less pronounced than those to the cues released by conspecifics. In our study, the two fish rely primarily on cues from individuals of their own species, possibly because they are the ones they encounter significantly more often than heterospecifics in the environment. 
On the other hand, behavioural responses of fish to alarm cues are highly plastic and reflect the overlap or differentiation between their ecological niches, as was demonstrated in juveniles and adults of sympatric sunfish: Lepomis macrochirus Rafinesque, 1819 and Lepomis gibbosus (Linnaeus, 1758) (Xia et al., 2018). We suppose that the recognition of heterospecific cues is suppressed by the fact that the prey guild and habitat overlap between the two species is not as strong as commonly assumed. It is worth noting that the tested specimens of both species differed in size, which reflects natural interspecific differences in the field. Nevertheless, it cannot be excluded that, if any of the studied behaviours are size-dependent, this may contribute to different responses of the species observed in our study.

In accordance with our second hypothesis, both species differed from each other in their anti-predation behaviour. Thigmotaxis was exhibited only by the gudgeon as a tendency to avoid the central part of the experimental tank and stay at its walls (wall-hugging). Thigmotaxis is a well-validated index of anxiety in animals (Schnörr et al., 2012). It can be assumed that this reaction is a passive and defensive attitude, reducing the risk of death (Węsierska \& Turlejski, 2000). In our study, the proximity of the walls/filter was the only shelter and probably increased the sense of safety in fish under predation risk. This clear preference for the peripheral part of the tank can be considered as increasing caution in exploring the environment by tested fish. Interestingly, instead of schooling, the gudgeon exhibited brief (during the initial 3-min sub-period) dispersion. It is generally accepted that schooling is a behavioural mechanism which decreases the probability of predation (Jarman, 1974; Magurran, 1990; Jachner, 1995). A predator facing aggregated prey may experience the confusion effect, i.e. difficulty in focusing on and picking a single individual from a group and therefore chances of escape of prey individuals increase (Heczko \& Seghers, 1981; Speedie \& Gerlai, 2008). Additionally, the likelihood of detection of predation risk by a shoal is greater than by a single individual (Jachner, 1995; Lima, 1995). We posit that the thigmotaxis and dispersion revealed by the gudgeon should be considered together. These two behaviours probably act together in the same direction to enhance the probability of success in seeking shelters. The monkey goby, in contrast to the gudgeon, gathered together when exposed to the alarm stimuli, though this reaction was the weakest among all those observed in our study and should be interpreted with caution. Both fish moved less in the presence of the alarm cue, but the response of the monkey goby here was weaker than that of the gudgeon. Only gudgeon reduced their horizontal movements and their reduction in vertical movements was greater than that of the monkey goby. Reduction in locomotor activity is a common antipredator defence induced by alarm cues (Mathis \& Smith, 1993a; Kopack et al., 2015). Potential prey individuals, while on the move, send clear visual and mechanical stimuli attracting the attention of predators (Sih, 1986; Johansson, 1992). Immobility helps avoid predators due to the reduction in water movements informing the predator of the presence of the prey individuals (Klemm, 2001; Barbosa-Júnior et al., 2010).

Thus, the monkey goby exhibited less pronounced anti-predator responses than the gudgeon (the lower number of different reaction types and lower intensity of those shown by both species). The lower responsiveness of the invasive monkey goby to the alarm cues could be attributed to their phylogenetical and ecological distance from the gudgeon. In nature, even closely related species within the same prey guild may differ in their responses to alarm cues, as shown for lobsters (Briones-Fourzán et al., 2006), flatfish (Boersma et al., 2008) and hemipteran bugs (Ferzoco et al., 2019). Thus, not only phylogenetic but also ecological aspects, such as habitat use, should be considered, including a combination of these factors (Sullivan et al., 2003), to understand the nature of the behavioural differences between the two species. Unfortunately, the in-depth research elucidating finescale differences in habitat use between the species with concomitant discrepancies in their behaviour is missing.

In connection with the weak anti-predator responses of the monkey goby and its high invasive potential in contrast to the gudgeon, a question arises whether these traits might be associated with the invasiveness. We tested two co-occurring species, one invasive, the other with no invasive history in the world. In some locations relative changes in their abundances were seen to coincide with the appearance of the invader (Jakovlić et al., 2015). It is worth noting that when an alien species enters a local assemblage and starts to compete with its members, the outcome of 
this competition depends on differences between them, rather than on its general comparisons with other biota all over the world. Therefore, it is not important whether its responses to predators are generally strong or weak, but how they compare to those of local, co-occurring competitors. Assuming that the monkey goby in new areas "escape" from their natural competitors and predators, the need for defence against the enemies may be reduced in contrast to the gudgeon, facing its natural enemies. The energy saved this way can be allocated, for example, into faster growth or more effective reproduction (Keane \& Crawley, 2002; Heger \& Jeschke, 2014). However, it cannot be excluded that the weaker responses of the monkey goby to the alarm cues result from its ability to assess the predation risk more efficiently compared to the gudgeon because alarm substances are not the only cues indicating predation risk (Wisenden, 2015) and they alone may be too little of a stimulus to encourage greater fear responses in the fish. In both cases, the observed differences may contribute to the advantage of the invasive species over the native one. Nevertheless, we admit this is just a correlational reasoning based on two species. Therefore, further studies on a higher number of species and cues associated with predation are needed to confirm whether the interspecific differences in behavioural responses to alarm cues observed in our study are related to the invasive potential.

We have shown that two co-existing bottomdwelling fish differ in their behavioural responses to predation cues, with the invasive species being generally less responsive than the non-invasive one. Moreover, both species turned out to be capable of detecting heterospecific alarm cues, which may be beneficial in a multi-species bottom fish assemblage. Nevertheless, their responses to conspecific alarms were clearly stronger than those to the other species' cues.

Acknowledgements We would like to thank Kit Magellan and an anonymous reviewer whose valuable comments improved the original manuscript. We are grateful to Mrs Hazel Pearson for language corrections. This research was supported by Polish National Science Centre (NSC Grant No. 2016/23/B/NZ8/00741).

Authors' contributions PK, TK, MPK, JK, RP and ŁJ collected and maintained fish. PK, JK, TK, ŁJ and RP conceived the ideas and designed methods. PK and MA conducted experiments under TK supervision. PK analysed video data. PK, JK and TK analysed data. PK, TK, JK and MPK wrote the manuscript. All authors contributed critically to the drafts and gave final approval for publication.

Funding This research was supported by Polish National Science Centre (NSC Grant No. 2016/23/B/NZ8/00741).

Data Availability The datasets generated and analysed during the current study are available from the corresponding author on request.

Code availability Not applicable.

\section{Declarations}

Conflict of interest The authors declare no competing interests.

Ethical approval We collected and used the fish under permit of the Local Committee for Ethics in Animal Research in Bydgoszcz, Poland, statement no. 50/2017 from 28 September 2017. All procedures using fish met the European Union guidelines on the protection of animals used for scientific purposes (Directive 2010/63/UE). We took care to ensure compliance with animal welfare guidelines to minimize the welfare impact on subjects. We carried out the fishing and transportation with great care to minimise the duration of these operations as we did the direct handling of the fish to avoid any harmful effects (e.g. injuries, scale loss) that might cause undue stress and mortality. During the acclimation period in the stock tanks, we did not observe any negative consequences of transport or stock conditions (the fish were active, foraged and occupied shelters and their mortality was sporadic). During the tests, we noticed neither injuries nor mortality. Each individual was tested only once. After the tests, we released the native gudgeon into the wild, whereas the monkey goby, because of their invasive status, had to be killed (with an overdose of MS-222) and disposed of according to the Regulation of the Polish Minister of the Environment from 9 September 2011 (Journal of Laws No. 210, item 1260). We kept the number of individuals killed in order to obtain the alarm substances to a minimum. Killing was carried out by a qualified person holding an appropriate certificate (No. 2355/2015) issued by the Polish Laboratory Animal Science Association.

Consent to participate Not applicable.

Consent for publication Not applicable.

Open Access This article is licensed under a Creative Commons Attribution 4.0 International License, which permits use, sharing, adaptation, distribution and reproduction in any medium or format, as long as you give appropriate credit to the original author(s) and the source, provide a link to the Creative Commons licence, and indicate if changes were made. The images or other third party material in this article are included in the article's Creative Commons licence, unless indicated otherwise in a credit line to the material. If material is not included in the article's Creative Commons licence and your intended use is not permitted by statutory regulation or exceeds 
the permitted use, you will need to obtain permission directly from the copyright holder. To view a copy of this licence, visit http://creativecommons.org/licenses/by/4.0/.

\section{References}

Allan, J. D., 1982. The effects of reduction in trout density on the invertebrate community of a mountain stream. Ecology 63: 1444-1455.

Anderson, K. A. \& A. Mathis, 2016. Friends in low places: responses of a benthic stream fish to intra-prey-guild alarm cues. Ethology 122: 954-962.

Bănărescu, P. M., V. M. Sorić \& P. S. Economidis, 1999. Gobio gobio (Linnaeus, 1758) In Bănărescu, P. M. (ed), The Freshwater Fishes of Europe Vol. 5/I. Cyprinidae 2. Part 1 Rhodeus to Capoeta AULA-Verlag, Wiebelsheim: 81-134.

Barbosa-Júnior, A., E. J. Magalhães, A. Hoffmann \& L. M. Ide, 2010. Conspecific and heterospecific alarm substance induces behavioral responses in piau fish Leporinus piau. Acta Ethologica 13: 119-126.

Barton, D. R., R. A. Johnson, L. Campbell, J. Petruniak \& M. Patterson, 2005. Effects of round gobies (Neogobius melanostomus) on dreissenid mussels and other invertebrates in Eastern Lake Erie, 2002-2004. Journal of Great Lakes Research 31: 252-261.

Błońska, D., J. Grabowska, J. Kobak, M. Rachalewski \& K. Bacela-Spychalska, 2016. Fish predation on sympatric and allopatric prey-A case study of Ponto-Caspian gobies, European bullhead and amphipods. Limnologica - Ecology and Management of Inland Waters 61: 1-6.

Boersma, K. S., C. H. Ryer, T. P. Hurst \& S. S. Heppell, 2008. Influences of divergent behavioral strategies upon risk allocation in juvenile flatfishes. Behavioral Ecology and Sociobiology 62: 1959-1968.

Borcherding, J., H. Arndt, S. Breiden, K. Brenner, L. Heermann, S. Höfer, C. Leistenschneider, J. Lindner, S. Staas \& S. Gertzen, 2016. Drift of fish larvae and juveniles in the Lower Rhine before and after the goby invasion. Limnologica - Ecology and Management of Inland Waters 59: 53-62.

Borcherding, J., S. Staas, S. Krüger, M. Ondračková, L. Šlapanský \& P. Jurajda, 2011. Non-native Gobiid species in the lower River Rhine (Germany): recent range extensions and densities. Journal of Applied Ichthyology 27: 153-155.

Briones-Fourzán, P., M. Pérez-Ortiz \& E. Lozano-Álvarez, 2006. Defense mechanisms and antipredator behavior in two sympatric species of spiny lobsters, Panulirus argus and P. guttatus. Marine Biology 149: 227-239.

Brönmark, C. \& L.-A. Hansson, 2000. Chemical communication in aquatic systems: an introduction. Oikos 88: 103-109.

Brown, G. E. \& J.-G.J. Godin, 1997. Anti-predator responses to conspecific and heterospecific skin extracts by threespine sticklebacks: alarm pheromones revisited. Behaviour 134: 1123-1134.
Burks, R. L. \& D. M. Lodge, 2002. Cued in: advances and opportunities in freshwater chemical ecology. Journal of Chemical Ecology 28: 1901-1917.

Čápová, M., I. Zlatnická, V. Kováč \& S. Katina, 2008. Ontogenetic variability in the external morphology of monkey goby, Neogobius fluviatilis (Pallas, 1814) and its relevance to invasion potential. Hydrobiologia 607: 17-26.

Chivers, D. P., D. L. Dixson, J. R. White, M. I. McCormick \& M. C. O. Ferrari, 2013. Degradation of chemical alarm cues and assessment of risk throughout the day. Ecology and Evolution 3: 3925-3934.

Chivers, D. P. \& R. J. F. Smith, 1998. Chemical alarm signalling in aquatic predator-prey systems: A review and prospectus. Écoscience 5: 338-352.

Chung-Davidson, Y.-W., M. Huertas \& W. Li, 2010. A review of research in fish pheromones. In Breithaupt, T. \& M. Thiel (eds), Chemical Communication in Crustaceans Springer, New York NY: 467-482.

Copp, G. H., P. G. Bianco, N. G. Bogutskaya, T. Erős, I. Falka, M. T. Ferreira, M. G. Fox, J. Freyhof, R. E. Gozlan, J. Grabowska, V. Kováč, R. Moreno-Amich, A. M. Naseka, M. Peňáz, M. Povž, M. Przybylski, M. Robillard, I. C. Russell, S. Stakènas, S. Šumer, A. Vila-Gispert \& C. Wiesner, 2005. To be, or not to be, a non-native freshwater fish? Journal of Applied Ichthyology 21: 242-262.

Crane, A. L., M. J. Lampe \& A. Mathis, 2013. Detecting danger from prey-guild members: behavioural and metabolic responses of Ozark zigzag salamanders to alarm secretions from earthworms. Ethology Ecology and Evolution 25: 377-387.

Dalesman, S., S. D. Rundle, D. T. Bilton \& P. A. Cotton, 2007. Phylogenetic relatedness and ecological interactions determine antipredator behavior. Ecology 88: 2462-2467.

Early, R., B. A. Bradley, J. S. Dukes, J. J. Lawler, J. D. Olden, D. M. Blumenthal, P. Gonzalez, E. D. Grosholz, I. Ibañez, L. P. Miller, C. J. B. Sorte \& A. J. Tatem, 2016. Global threats from invasive alien species in the twenty-first century and national response capacities. Nature Communications 7: 12485.

Egger, B., J. Wiegleb, F. Seidel, P. Burkhardt-Holm \& P. E. Hirsch, 2021. Comparative swimming performance and behaviour of three benthic fish species: the invasive round goby (Neogobius melanostomus), the native bullhead (Cottus gobio), and the native gudgeon (Gobio gobio). Ecology of Freshwater Fish 30: 391-405.

Ferrari, M. C. O., B. D. Wisenden \& D. P. Chivers, 2010. Chemical ecology of predator-prey interactions in aquatic ecosystems: a review and prospectus. Canadian Journal of Zoology 88: 698-724.

Ferzoco, I. M. C., C. B. Baines \& S. J. McCauley, 2019. Cooccurring Notonecta (Hemiptera: Heteroptera: Notonectidae) species differ in their behavioral response to cues of Belostoma (Hemiptera: Heteroptera: Belostomatidae) predation risk. Annals of the Entomological Society of America 112: 402-408.

Gallardo, B., M. Clavero, M. I. Sánchez \& M. Vilà, 2016. Global ecological impacts of invasive species in aquatic ecosystems. Global Change Biology 22: 151-163. 
Grabowska, J., T. Kakareko, D. Błońska, M. Przybylski, J. Kobak, Ł. Jermacz \& G. H. Copp, 2016. Interspecific competition for a shelter between non-native racer goby and native European bullhead under experimental conditions - Effects of season, fish size and light conditions. Limnologica - Ecology and Management of Inland Waters 56: $30-38$.

Grabowska, J., J. Kotusz \& A. Witkowski, 2010. Alien invasive fish species in Polish waters: an overview. Folia Zoologica 59: 73-85.

Hay, M. E., 2009. Marine chemical ecology: chemical signals and cues structure marine populations, communities, and ecosystems. Annual Review of Marine Science 1: 193-212.

Hazlett, B. A., A. Burba, F. Gherardi \& P. Acquistapace, 2003. Invasive species of crayfish use a broader range of predation-risk cues than native species. Biological Invasions 5: 223-228.

Heczko, E. J. \& B. H. Seghers, 1981. Effects of alarm substance on schooling in the common shiner (Notropis cornutus, Cyprinidae). Environmental Biology of Fishes 6: 25-29.

Heger, T. \& J. M. Jeschke, 2014. The enemy release hypothesis as a hierarchy of hypotheses. Oikos 123: 741-750.

Jachner, A., 1995. Changes in feeding behavior of bleak ( $A l$ burnus alburnus L.) in response to visual and chemical stimuli from predators. Archiv Für Hydrobiologie 133: 305-314.

Jakovlić, I., M. Piria, N. Šprem, T. Tomljanović, D. Matulić \& T. Treer, 2015. Distribution, abundance and condition of invasive Ponto-Caspian gobies Ponticola kessleri (Günther, 1861), Neogobius fluviatilis (Pallas, 1814), and Neogobius melanostomus (Pallas, 1814) in the Sava River basin, Croatia. Journal of Applied Ichthyology 31: 888-894.

Jakubčinová, K., P. Simonović, B. Števove, J. Čanak Atlagić \& V. Kováč, 2017. What can morphology tell us about ecology of four invasive goby species? Journal of Fish Biology 90: 1999-2019.

Jarman, P. J., 1974. The social organisation of antelope in relation to their ecology. Behaviour 48: 215-267.

Johansson, F., 1992. Predator life style and prey mobility: a comparison of two predatory odonate larvae. Archiv Für Hydrobiologie 126: 163-173.

Jurajda, P., J. Černý, M. Polačik, Z. Valová, M. Janáč, R. Blažek \& M. Ondračková, 2005. The recent distribution and abundance of non-native Neogobius fishes in the Slovak section of the River Danube. Journal of Applied Ichthyology 21: 319-323.

Kakareko, T., D. Płąchocki \& J. Kobak, 2009. Relative abundance of Ponto-Caspian gobiids in the lower Vistula River (Poland) 3- to 4 years after first appearance. Journal of Applied Ichthyology 25: 647-651.

Kakareko, T., J. Kobak, J. Grabowska, Ł. Jermacz, M. Przybylski, M. Poznańska, D. Pietraszewski \& G. H. Copp, 2013. Competitive interactions for food resources between invasive racer goby Babka gymnotrachelus and native European bullhead Cottus gobio. Biological Invasions 15: 2519-2530.
Kakareko, T., J. Kobak, M. Poznańska, Ł. Jermacz \& G. H. Copp, 2016. Underwater evaluation of habitat partitioning in a European river between a non-native invader, the racer goby and a threatened native fish, the European bullhead. Ecology of Freshwater Fish 25: 60-71.

Keane, R. M. \& M. J. Crawley, 2002. Exotic plant invasions and the enemy release hypothesis. Trends in Ecology \& Evolution 17: 164-170.

Keller, R. P., J. Geist, J. M. Jeschke \& I. Kühn, 2011. Invasive species in Europe: ecology, status, and policy. Environmental Sciences Europe 23: 23.

Klemm, W. R., 2001. Behavioral arrest: in search of the neural control system. Progress in Neurobiology 65: 453-471.

Kopack, C. J., E. Dale Broder, J. M. Lepak, E. R. Fetherman \& L. M. Angeloni, 2015. Behavioral responses of a highly domesticated, predator naïve rainbow trout to chemical cues of predation. Fisheries Research 169: 1-7.

Kottelat, M. \& J. Freyhof, 2007. Handbook of European Freshwater Fishes, Publications Kottelat, Cornol and Freyhof, Berlin.

Landeira-Dabarca, A., J. Näslund, J. I. Johnsson \& M. Álvarez, 2019. Cue recognition and behavioural responses in the three-spined stickleback (Gasterosteus aculeatus) under risk of fish predation. Acta Ethologica 22: 209-221.

Liley, N. R., 1982. Chemical communication in fish. Canadian Journal of Fisheries and Aquatic Sciences 39: 22-35.

Lima, S. L., 1995. Back to the basics of anti-predatory vigilance: the group-size effect. Animal Behaviour 49: 11-20.

Lima, S. L. \& L. M. Dill, 1990. Behavioral decisions made under the risk of predation: a review and prospectus. Canadian Journal of Zoology 68: 619-640.

Łaszewski, M. A., 2018. Diurnal water temperature dynamics in lowland rivers: a case study from Central Poland. Journal of Water and Land Development 36: 89-97.

Magellan, K., A. J. Booth \& O. L. F. Weyl, 2020. Innate responses to conspecific and heterospecific alarm cues in the endangered eastern cape redfin Pseudobarbus afer. Journal of Fish Biology 96: 1284-1290.

Magurran, A. E., 1990. The adaptive significance of schooling as an anti-predator defence in fish. Annales Zoologici Fennici 27: 51-66.

Mathis, A. \& R. J. F. Smith, 1993a. Intraspecific and crosssuperorder responses to chemical alarm signals by brook stickleback. Ecology 74: 2395-2404.

Mathis, A. \& R. J. F. Smith, 1993b. Chemical alarm signals increase the survival time of fathead minnows (Pimephales promelas) during encounters with northern pike (Esox lucius). Behavioral Ecology 4: 260-265.

Mathuru, A. S., 2016. Conspecific injury raises an alarm in medaka. Scientific Reports 6: 36615.

Mendel, J., S. Lusk, E. D. Vasil'eva, V. P. Vasil'ev, V. Lusková, F. G. Ekmekci, F. Erk'akan, A. Ruchin, J. Koščo, L. Vetešník, K. Halačka, R. Šanda, A. N. Pashkov \& S. I. Reshetnikov, 2008. Molecular phylogeny of the genus Gobio Cuvier, 1816 (Teleostei: Cyprinidae) and its contribution to taxonomy. Molecular Phylogenetics and Evolution 47: 1061-1075. 
Mikl, L., Z. Adámek, K. Roche, L. Všetičková, L. Šlapanský \& P. Jurajda, 2017. Invasive Ponto-Caspian gobies in the diet of piscivorous fish in a European lowland river. Fundamental and Applied Limnology 190: 157-171.

Mirza, R. S. \& D. P. Chivers, 2001. Are chemical alarm cues conserved within salmonid fishes? Journal of Chemical Ecology 27: 1641-1655.

Mirza, R. S., S. A. Fisher \& D. P. Chivers, 2003. Assessment of predation risk by juvenile yellow perch, Perca flavescens: Responses to alarm cues from conspecifics and prey guild members. Environmental Biology of Fishes 66: 321-327.

Naseka, A. M. \& N. G. Bogutskaya, 2009. Fishes of the Caspian Sea: zoogeography and updated check-list. Zoosystematica Rossica 18: 295-317.

Nelson, J. S., T. C. Grande \& M. V. H. Wilson, 2016. Fishes of the World, John Wiley \& Sons, Hoboken NJ.

Penczak, T., A. Kruk, G. Zięba, L. Marszał, H. Koszaliński, S. Tybulczuk \& W. Galicka, 2006. Fish fauna in the Pilica River system in the fifth decade of study. Part I. Pilica River. Scientific Annual of the Polish Angling Association 19: 103-122.

Plachá, M., M. Balážová, V. Kováč \& S. Katina, 2010. Age and growth of non-native monkey goby Neogobius fluviatilis (Teleostei, Gobiidae) in the River Ipel', Slovakia. Folia Zoologica 59: 332-340.

Płąchocki, D., J. Kobak \& T. Kakareko, 2012. First report on the importance of alien gobiids in the diet of native piscivorous fishes in the lower Vistula River (Poland). Oceanological and Hydrobiological Studies 41: 83-89.

Płąchocki, D., J. Kobak, M. Poznańska-Kakareko \& T. Kakareko, 2020. Environmental factors associated with the occurrence of the Ponto-Caspian gobies in a lowland river belonging to the central European invasion corridor. River Research and Applications 36: 25-35.

Pollock, M. S. \& D. P. Chivers, 2004. The effects of density on the learned recognition of heterospecific alarm cues. Ethology 110: 341-349.

Pollock, M. S., D. P. Chivers, R. S. Mirza \& B. D. Wisenden, 2003. Fathead minnows, Pimephales promelas, learn to recognize chemical alarm cues of introduced brook stickleback, Culaea inconstans. Environmental Biology of Fishes 66: 313-319.

Reyjol, Y., P. Brodeur, Y. Mailhot, M. Mingelbier \& P. Dumont, 2010. Do native predators feed on non-native prey? The case of round goby in a fluvial piscivorous fish assemblage. Journal of Great Lakes Research 36: 618-624.

Ricciardi, A. \& H. J. MacIsaac, 2010. Impacts of biological invasions on freshwater ecosystems. In Richardson, D. M. (ed), Fifty Years of Invasion: Ecology The Legacy of Charles Elton Wiley-Blackwell, Hoboken NJ: 211-224.

Roche, K. F., M. Janač \& P. Jurajda, 2013. A review of Gobiid expansion along the Danube-Rhine corridor-geopolitical change as a driver for invasion. Knowledge and Management of Aquatic Ecosystems 411: 01.

Schnörr, S. J., P. J. Steenbergen, M. K. Richardson \& D. L. Champagne, 2012. Measuring thigmotaxis in larval zebrafish. Behavioural Brain Research 228: 367-374.

Seppänen, J.-T., J. T. Forsman, M. Mönkkönen \& R. L. Thomson, 2007. Social information use is a process across time, space, and ecology, reaching heterospecifics. Ecology 88: 1622-1633.
Sih, A., 1986. Antipredator responses and the perception of danger by mosquito larvae. Ecology 67: 434-441.

Smith, R. J. F., 1992. Alarm signals in fishes. Reviews in Fish Biology and Fisheries 2: 33-63.

Sorensen, P. W., 2015. Introduction to pheromones and related chemical cues in fishes. In Sorensen, P. W. \& B. D. Wisenden (eds), Fish Pheromones and Related Cues Wiley-Blackwell, Hoboken NJ: 1-9.

de Souza-Bastos, L. R., C. A. Freire \& M. Fernandes-de-Castilho, 2014. Skin extract from Rhamdia quelen (Siluriformes: Heptapteridae) does not promote stress in conspecifics. Neotropical Ichthyology 12: 125-132.

Speedie, N. \& R. Gerlai, 2008. Alarm substance induced behavioral responses in zebrafish (Danio rerio). Behavioural Brain Research 188: 168-177.

Stabell, O. B. \& M. S. Lwin, 1997. Predator-induced phenotypic changes in crucian carp are caused by chemical signals from conspecifics. Environmental Biology of Fishes 49: 145-149.

Strayer, D. L., 2010. Alien species in fresh waters: ecological effects, interactions with other stressors, and prospects for the future. Freshwater Biology 55: 152-174.

Sullivan, A. M., D. M. Madison \& J. R. Rohr, 2003. Behavioural responses by red-backed salamanders to conspecific and heterospecific cues. Behaviour 140: 553-564.

Thacker, C. E. \& D. M. Roje, 2011. Phylogeny of Gobiidae and identification of gobiid lineages. Systematics and Biodiversity 9: 329-347.

Tworoger, S. S. \& S. E. Hankinson, 2006. Collection, processing, and storage of biological samples in epidemiologic studies: sex hormones, carotenoids, inflammatory markers, and proteomics as examples. Cancer Epidemiology Biomarkers and Prevention 15: 1578-1581.

Van Kessel, N. V., M. Dorenbosch, M. R. M. De Boer, R. S. E. W. Leuven \& G. Van der Velde, 2011. Competition for shelter between four invasive gobiids and two native benthic fish species. Current Zoology 57: 844-851.

Vilà, M., C. Basnou, P. Pyšek, M. Josefsson, P. Genovesi, S. Gollasch, W. Nentwig, S. Olenin, A. Roques, D. Roy, P. E. Hulme \& DAISIE partners, 2010. How well do we understand the impacts of alien species on ecosystem services? A pan-European, cross-taxa assessment. Frontiers in Ecology and the Environment 8: 135-144.

Weis, J. S., 2016. Eat or be Eaten: Invasion and Predation in Aquatic Ecosystems. In Weis, J. S. \& D. Sol (eds), Biological Invasions and Animal Behaviour Cambridge University Press, Cambridge: 180-198.

Węsierska, M. \& K. Turlejski, 2000. Spontaneous behavior of the gray short-tailed opossum (Monodelphis domestica) in the elevated plus-maze: comparison with Long-Evans rats. Acta Neurobiologiae Experimentalis 60: 479-487.

Wisenden, B. D., 2003. Chemically mediated strategies to counter predation. In Collin, S. P. \& N. J. Marshall (eds), Sensory Processing in Aquatic Environments Springer, New York NY: 236-251.

Wisenden, B. D., 2015. Chemical cues that indicate risk of predation. In Sorensen, P. W. \& B. D. Wisenden (eds), Fish Pheromones and Related Cues John Wiley \& Sons, Hoboken NJ: 131-148.

Wisenden, B. D. \& D. P. Chivers, 2006. The role of public chemical information in antipredator behavior. In Ladich, 
F., S. P. Collin, P. Moller \& B. G. Kapoor (eds), Communication in Fishes Science Publishers, Enfield NH: 259-278.

Xia, J., C. K. Elvidge \& S. J. Cooke, 2018. Niche separation, ontogeny, and heterospecific alarm responses in centrarchid sunfish. Behavioral Ecology 29: 862-868.
Publisher's Note Springer Nature remains neutral with regard to jurisdictional claims in published maps and institutional affiliations. 